\title{
Psychological Experiences of Patients with COVID-19: A Phenomenological Study
}

\author{
Siqian Wang, MSN, $R N^{1}$, Yingjie Liu, MSN, $R N^{2,3}$, Hangying She, $B S N, R N^{1}$, Tongyao Wang, $B S N, R N^{1}$, Jie \\ Chen, $B S N$, $R N^{2,3}$, Xingmei Feng, $B S N, R N^{2,3}$, Chao-Pin Hsiao, PhD, $R N, F A A N^{1^{*}}$ \\ ${ }^{1}$ Frances Payne Bolton School of Nursing, Case Western Reserve University, Cleveland, Ohio, USA \\ ${ }^{2} 988^{\text {th }}$ Hospital of People's Liberation Army, Zhengzhou, China \\ ${ }^{3}$ Tai Kang Tongji Hospital, Wuhan, China
}

\begin{abstract}
Background: Millions of lives have been affected and under psychological distress amid the coronavirus disease (COVID-19) pandemic. However, existing studies mainly focused on the physical or psychological experiences and symptoms in the uninfected public or healthcare providers. There is high risk and difficulty conducting interviews with patients in a COVID-19 ward; consequently, the psychological experiences of patients with COVID-19 have not been adequately explored.
\end{abstract}

Objectives: The purpose of this phenomenological study was to describe the psychological experiences of patients with COVID-19 from prior-to-diagnosis to discharge, as well as the sources of support during hospitalization.

Methods: Using a phenomenological approach, we studied 15 hospitalized patients with COVID-19 in the Taikang Tongji Hospital. We used purposive sampling to recruit 15 study participants. Semi-structured in-depth interviews and observations were used to collect data from each participant. Data were analyzed using Colaizzi's method.

Results: Fifteen patients with COVID-19 (seven males and eight females) were enrolled in the study. Participants were aged between 13 and $91(M=55.86, S D=22.94)$. Five themes of the psychological experiences were generated from15 patients with COVID-19. These themes are: 1) Misjudgment of the disease before diagnosis; 2) Negative emotions at the diagnosis; 3) Psychological agony during hospitalization; 4) Expectancy towards discharge, and 5) Support during hospitalization.

Discussion: This study demonstrates that patients with COVID-19 have complicated psychological experiences, from prior-to-diagnosis to discharge. The findings suggest that healthcare providers should be aware of the severe psychological distress of patients with COVID-19 and should develop mental health interventions accordingly.

\section{Keywords}

Coronavirus disease 2019 (COVID-19), Patient, Psychological experiences

\section{Introduction}

The coronavirus disease (COVID-19) is a severe acute respiratory syndrome. It is caused by the infection of severe acute respiratory syndrome coronavirus 2 (SARS-CoV-2) [1]. The first cases were detected in Wuhan, China, and reported to the World Health Organization (WHO) on December 31, 2019 [2]. Forty-one patients were confirmed as having COVID-19 infection in Wuhan in early January 2020 [3]. Due to the rapid spread of person-to-person transmission, 7,734 confirmed cases were identified in mainland China by end of January 2020 [4]. Despite the immediate response to this emergency, the virus has spread quickly over 216 countries and territories, with 4,307,287 confirmed cases and 295,101 confirmed deaths at the time of this manuscript's completion [5].
COVID-19 has a fairly long incubation period and is highly contagious, with an ability for fast and widespread transmission $[6,7]$. The main clinical symptoms include fever, fatigue, and dry cough; some patients have concomitant symptoms such as nasal congestion, runny nose, and gastrointestinal up-

*Corresponding author: Asst. Prof. Chao-Pin Hsiao, MSN, PhD, RN, Frances Payne Bolton School of Nursing, Case Western Reserve University, 10900 Euclid Ave., Cleveland, Ohio 441064904, Tell: 216-368-3343, Fax: 216-368-3542

Accepted: November 24, 2020

Published online: November 26, 2020

Citation: Wang S, Liu Y, She H, et al. (2020) Psychological Experiences of Patients with COVID-19: A Phenomenological Study. J Nurs Pract 3(1):193-201 
set; in severe cases, patients can develop shortness of breath [8]. Amid this pandemic, millions of lives, including those of patients, frontline healthcare workers, informal caregivers, children and older adults, have been affected. The United Nations and the WHO warned about the extreme impact of COVID-19 on mental health and appealed for substantial investment in mental health services [9]. Meanwhile, a number of researchers reported that people experienced psychological distress during the pandemic, including moderate to high depression, anxiety, and stress [10-13]. However, the researchers' studies mainly focused on the experiences of psychological distress and symptoms of healthcare providers, college students, healthy older adults, and the general public. Because of the risk and difficulty in conducting interviews in hospital wards, a significant group of COVID-19 patients was overlooked and had not been explored. The gap lies in the lack of knowledge about the psychological experiences of these patients at the initiation of the study.

To our knowledge, this is the first attempt using a qualitative method to explore and describe the psychological experiences of COVID-19 patients from the following phrases: Prior to diagnosis, at diagnosis, during hospitalization, and at the time of discharge. Some of the authors of this study worked as frontline nurses who observed the phenomenon of psychological distress, conducted face-to-face interviews of patients with COVID-19, and attempted to understand their experiences during this pandemic. Furthermore, we describe the sources of support during hospitalization. The study results will contribute scientific knowledge to nursing research and practice, and provide references for other investigators when they encounter similar pandemics in the future.

\section{Methods}

\section{Study design}

A phenomenological research design was used to explore the psychological experiences of patients with COVID-19 from diagnosis to discharge, and to describe the sources of support during hospitalization.

\section{Sample and setting}

Fifteen patients with COVID-19 were recruited using purposive sampling from the Taikang Tongji hospital. In order to meet our diagnostic criteria, all the patients were laboratory confirmed as COVID-19 positive by checking samples from the respiratory system via viral tests. All participants have mild-to-moderate clinical conditions of COVID-19 including fever, fatigue, dry cough or gastrointestinal upset. All participants were taking general care for COVID-19 in the Taikang Tongji hospital at that time. The sample size was decided when saturation was reached. Among the 15 participants, one is a 13-year-old adolescent. We decided to keep this adolescent because:1) He fit in our inclusion criteria; 2) His symptoms are mild-moderate and vital signs are stable; 3) Our interview questions are simple questions, adolescent has the capacity to understand simple questions and to express his thoughts; 4) Although adolescent may have his own way to understand and express his experience, it reflects his accurate data; 5) Including participants ages between 13 and 91 would make our data more inclusive and representative. The inclusion criteria are listed as follows: 1) Hospitalized with a diagnosis of COVID-19; 2) Able to understand and speak Chinese; and 3) Able to participate in a conversation of 20 minutes at a time. Exclusion criteria included; 1 ) Patients were clinically diagnosed with psychological disorder (e.g., depression, anxiety, thought disorders, etc.); 2) Patients with documented cognitive impairment.

\section{Data collection}

Data collection occurred over a two-month period from February 2020 to April 2020. Data were collected by semi-structured in-depth interviews and observations [14]. Researcher started the conversations with opening questions like "tell me about what it was like for you to live through this experience of COVID-19;" "I would like you to focus more on how you felt mentally and emotionally rather than your physical symptoms, even though I understand that somewhat the former affects the latter". In addition, each study participant was asked the following five open-ended questions: 1) Tell me about your initial understanding of COVID-19 before you were diagnosed?; 2) How did you respond to COVID-19 and what was your feeling after being infected?; 3) What was your attitude towards the treatment?; 4) What did you need psychologically? Or what kind of support did you need?; 5) After your recovery, what new insights can you add to the meaning of your life?

In a total period of 60-75 minutes, two researchers collaborated on an audio recorded, semi-structured, and in-depth interview for each research participant, where one researcher conducted the interview and the other observed and recorded. In order to avoid a long-time contact with one participant and to ensure participants' safety and well-being, each interview was partitioned into three parts, 20-25 minutes for each part. Interviews were arranged in the late afternoons or evenings to avoid the peak hours of treatment and care, to ensure a quiet and uninterrupted environment for the participants to fully express their psychological experiences in detail.

\section{Data analysis}

Colaizzi's method was used to analyze qualitative data collected in this study with NVivo data analysis software. The Colaizzi's method includes seven steps: 1) Familiarizing with the transcripts; 2) Identifying significant statements; 3) Formulating meanings from the significant statements; 4) Clustering themes and subthemes from the formulated meanings; 5) Developing an exhaustive description; 6) Producing the structure of the phenomenon, and 7) Seeking verification of the results from the study participants [15]. In our study, two researchers were involved in the process of transcription: One converted the audio recordings to transcripts verbatim, and the other checked the transcripts verbatim against the audio recordings. Then, the primary researcher conducted the coding process. The result of each analytical report was confirmed by the corresponding participant. 
Citation: Wang S, Liu Y, She H, et al. (2020) Psychological Experiences of Patients with COVID-19: A Phenomenological Study. J Nurs Pract 3(1):193-201

Table 1: Demographics of participants $(\mathrm{N}=15)$.

\begin{tabular}{|c|c|c|c|}
\hline Characteristics & & $\mathbf{N}(\%)$ or Mean (SD) & Median (range) \\
\hline \multirow[t]{3}{*}{ Gender } & Male & $7(47 \%)$ & \multirow{15}{*}{59 (13 91) } \\
\hline & Female & $8(53 \%)$ & \\
\hline & & & \\
\hline Age & & $55.86(22.94)$ & \\
\hline \multirow[t]{4}{*}{ Occupation } & Employed & $5(33 \%)$ & \\
\hline & Retired & $5(33 \%)$ & \\
\hline & Student & $2(13 \%)$ & \\
\hline & Unemployed & $2(13 \%)$ & \\
\hline \multirow[t]{3}{*}{ Educational level } & Master & $1(6 \%)$ & \\
\hline & Associate or Bachelor & $5(33 \%)$ & \\
\hline & High school or below & $9(60 \%)$ & \\
\hline \multirow[t]{2}{*}{ Living condition } & Alone & $2(13 \%)$ & \\
\hline & With family & $13(87 \%)$ & \\
\hline \multirow[t]{2}{*}{ Chronic disease } & Yes & $8(53 \%)$ & \\
\hline & No & $7(47 \%)$ & \\
\hline
\end{tabular}

\section{Ethics and trustworthiness}

This study was approved by the Institutional Review Board (IRB) at the Taikang Tongji Hospital and at the $988^{\text {th }}$ hospital of People's Liberation Army. Due to various handicaps to participants' normal reading and writing during their hospitalization, a waiver of written consent was approved by the IRB that allowed researchers to obtain verbal consent from study participants. For the adolescent at the age of 13, a parental permission and an adolescent assent were obtained verbally and subsequently documented. Data were de-identified and stored in a password-protected computer for participants' confidentiality.

In order to obtain credibility, two researchers were involved in each data collection. Being frontline nurses, these two researchers engaged to stay involved and build trust with the patient participants in order to better observe and understand them. Research results were confirmed by the study participants to ensure the accuracy of the analyses and interpretations. Observations of participants' emotions and body languages were documented. Overall, investigator triangulation, prolonged engagement, and member checking were used to enhance credibility $[16,17]$. Field notes, raw audio-recorded data, and transcripts were kept and provided confirmability [18]. Bracketing was used to mitigate personal bias [19].

\section{Results}

Fifteen study participants, seven males (47\%) and eight females (53\%), were enrolled in this study. Participants were aged between 13 and $91(M=55.86, S D=22.94)$. More than half of the participants (60\%) had an educational level of high school or below, five participants (33\%) had an associate or a bachelor's degree, and one (6\%) had a master's degree. Most of the participants (87\%) lived with family members; $13 \%$ of the participants lived alone. About half of the participants (53\%) had chronic diseases. Table 1 describes the demographics of the participants. We extracted 5 themes and 13 subthemes that covered a span of complicated psychological experiences of patients with COVID-19 from prior-to-diagnosis to discharge (Figure 1). Table 2 illustrates an example of data processing - how themes were generated from the quotations.

\section{Theme 1: Misjudgment of the disease before di- agnosis}

In the first phrase of the spread of COVID-19, its potential victims faced an unprecedented situation caused by a pandemic that few people could have anticipated. Judgment regarding COVID-19 risks of infection was as complicated and uncertain as the virus appeared to be to the public, and a lax initial response by many people was based on two main factors: Lack of information on COVID-19, and indifference towards its risks.

\section{Lack of information}

The lack of information and inadequate knowledge among COVID-19 patients in varying circumstances was highly detrimental and facilitated the spread of the disease. The following example illustrates a case in which the patient didn't even know about the existence of the virus.P4: "My parents were busy preparing for Chinese Lunar New Year and promised to take me to my grandma's place in Chongqing. I was looking forward to playing with my cousin, and never realized the existence of this virus."

Another type of lack of information is shown, however, as a result of multiple contradictory sources, which essentially 


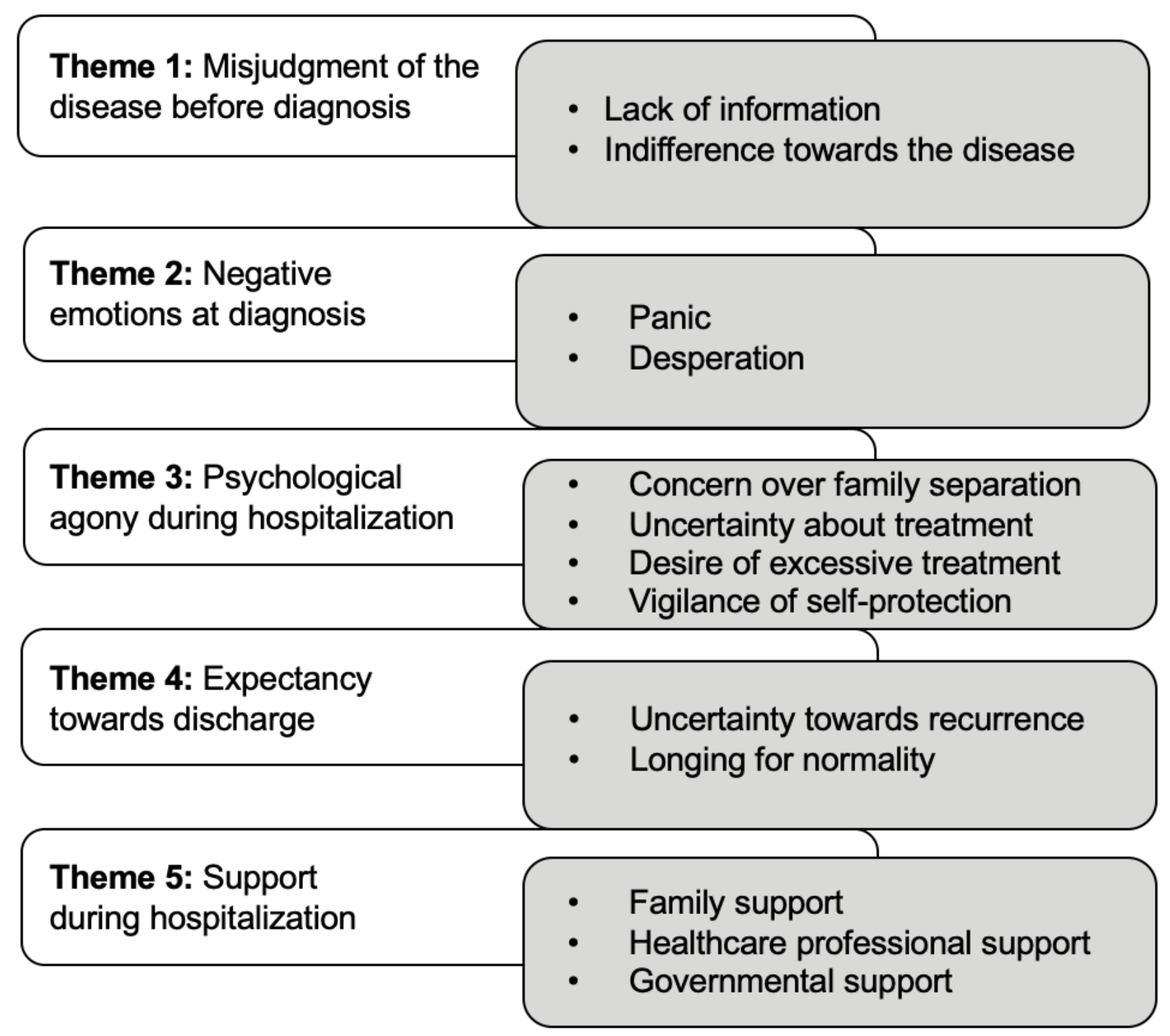

Figure 1: Patients with COVID-19 describe a series of complicated psychological experiences, from diagnosis and hospitalization to hospital discharge. The progression of these experiences includes the following phases: Misjudgment of the disease before diagnosis reflected by a lack of information or indifference towards the disease; negative emotions at the time of diagnosis that range from panic to desperation; psychological agony during hospitalization that includes concern over family separation, uncertainty about treatment, desire for excessive treatment, vigilance of self-protection during recovery; expectancy towards hospital discharge, which includes uncertainty about re-infection and longing for a return to normal life; and support during hospitalization from varying sources, including family, healthcare professionals, and government.

Table 2: Example of the process from quotations to theme.

\begin{tabular}{|l|l|l|}
\hline Theme & Subtheme & Quotations \\
\hline $\begin{array}{l}\text { Theme 2: Negative } \\
\text { emotions at diagnosis }\end{array}$ & Panic & $\begin{array}{l}\text { "Receiving the call that I was positive in the test for COVID-19, my mind went blank. Everyone } \\
\text { was panic-stricken. I had not planned for this, and could not imagine what could come of it." } \\
\text { (P3) } \\
\text { "My dad was the first person infected in our family, and then me and my mom. I remember we } \\
\text { began to panic. My mom made many phone calls, and she was frantic." (P4) }\end{array}$ \\
\hline Desperation & $\begin{array}{l}\text { "I tested positive. When I learned the test result, I felt complicated emotions. Time after time I } \\
\text { fell into desperation, yet I rallied, but then, desperation overcame me once again." (P8) }\end{array}$ \\
\hline & $\begin{array}{l}\text { "I still remember the day that the virus hit my family; first my grandma, then my dad, and later } \\
\text { my sister and me. What replayed again and again in my head was my grandma suffering and my } \\
\text { dad crying. Everyone in the family was in sheer desperation." (P7) }\end{array}$ \\
\hline
\end{tabular}


caused a lack of effective information that the patient could have relied upon. P3: "I had heard of the severity of this disease. But I didn't know which sources of information I should follow, nor did I know how to self-protect accordingly."

\section{Indifference towards the disease}

Indifference emphasized the subjective attitude about COVID-19 that reflected either intentional ignorance or an unintentional neglect of concern regarding the outbreak of the disease. For example, P1: "Although I lived alone, my kids would come visit me every day. One day, my son told me about this disease, but I never paid attention to it." Also, P8: "I had heard of the admission of COVID-19 patients into some hospitals. I didn't take it to heart; I let it go. What on earth is this virus? How was it spread? I didn'tknow. I didn't think I would be infected until the city was shut down."

While P1 and P8 neglected the importance of COVID-19 because of incognizance, the following two cases demonstrated an intentional disregard for the disease because of an overly optimistic misconception about their own personal health. P9: "I had heard of such patients in the hospital. But I didn't work in the hospital and was in good health. So, I thought COVID-19 was pretty far away from me and I would never have contact with the disease."P11: "I had to take care of the entire family, including my son and daughter. I would have no fear even if I were infected."

\section{Theme 2: Negative emotions at diagnosis}

At the time being diagnosed, the study participants responded in different levels of negative emotions, including being panic-stricken and desperate. Even though these negative emotions mentioned may coexist in the patients and are sometimes intertwined, we chose to focus on keynotes of their respective emotions, as the following examples illustrate:

\section{Panic}

For most of these COVID-19 patients, panic was a primal response when they were informed of their positive test results for the virus. P3: "Receiving the call that I was positive in the test for COVID-19, my mind went blank. Everyone was panic-stricken. I had not planned for this, and could not imagine what could come of it."P4: "My dad was the first person infected in our family, and then me and my mom. I remember we began to panic. My mom made many phone calls, and she was frantic."

\section{Desperation}

After a period of panicking, many of the patients fell into a state of desperation, frequently compounded by the other negative emotions like helplessness or restlessness. It is hard to tell which one is the leading emotion of a single patient at this phrase, but the emotion reflected the clearest to the interviewers is desperation. P8 (crying): "I tested positive. When I learned the test result, I felt complicated emotions. Time after time I fell into desperation, yet I rallied, but then, desperation overcame me once again." $P 7$ (the person tears up): "I still remember the day that the virus hit my family; first my grandma, then my dad, and later my sister and me. What replayed again and again in my head was my grandma suffering and my dad crying. Everyone in the family was in sheer desperation."

\section{Theme 3: Psychological agony during hospital- ization}

The negative emotions of these COVID-19 patients did not fade away quickly when they began medical treatment in the hospital. On the contrary, these patients experienced longterm psychological struggles, a phase in the maturation of their mental and emotional outlook during the recovery process. This psychological agonizing and recovering process can be as draining as the physical recovery from the illness. It can include deep worry and shame about the interruption of family responsibilities, or even self-protective behavior, such as a fear of and unwillingness to share a room with other patients. These several behaviors can be characterized into the following subthemes: Concern over family separation, uncertainty about treatment, desire for excessive medical treatment, and vigilance about self-protection.

\section{Concern over family separation}

When separated from family and quarantined for a prolonged length of time, these patients tended to ponder over their family responsibilities, worry about the future fulfillment of those responsibilities, and thus fall into anxiety and depression over the long-term separation from their loved ones. P13: "My grandson was preparing for the college entrance exam this year. Neither of his parents were home. He is home alone. How will he survive in the following days? I am staying here, worrying a lot about him."P9 (crying):"My husband and I were separated to different hospitals. My kids had been placed in foster care. It was a fatal blow to my family. I still tested positive in a recent health examination. I am far from discharge. I am not sure when I will be able to see my children."

\section{Uncertainty about treatment}

Another psychological struggle that patients have experienced during hospitalization is their uncertainty about the current treatment they have been undertaking. P1: "My body temperature was very unstable recently. I had fevers frequently. It was 37.9 oC yesterday. What would be happening if I were fever again? How they were going to treat me?" P6: "I have been under this treatment for more than two months. They have tried many medicines on me. But I was still positive. How do I deal with that?"

\section{Desire for excessive treatment}

Aside from these patients' uncertainty about their medical treatment for COVID-19, patients exhibited a desire to receive excessive medical treatment during hospitalization. All the patients, regardless of the severity of their symptoms or the length of their courses of treatment, yearned for a prompt, systematical, and complete examination and treatment. P14: "I have been asking the doctor about whether I need to get the oxygen or not. I heard that inhaling oxygen would be the best therapy."P5: "My heartbeat was pretty high those days. I felt dizzy, but not because of hunger. Can I 
get a thorough examination? I told this to the doctor, but he said these symptoms were due to my worries. I just want a thorough examination. I am pretty calm."

\section{Vigilance of self-protection}

A benign sign of recovery in these patients, whether psychologically or physically, was regaining vigilance about protecting their health during the treatment process. In our interviews, we noted that eight participants responded that they were not willing to accept new patients into their own rooms. Some even adamantly refused them. This refusal of room-sharing, although self-centered, gives the patients de facto spatial adequacy, capacious enough for both the physical recovery and mental consolation. P2: "I am close to being discharged. I do not understand why the hospital put another patient in my room. I do not know his health status. What if I get infected again? This means a lot to me." P15: "Some days ago, the hospital admitted a new patient to my room. I didn't dare to stay in the room and sit on my bed. I remained in the corridor. I talked with the nurse about it and she relayed my concerns to the doctor. Until I was told it was safe, I did not return to the room. I never took off my mask in my room, and when dining, I ate out in the corridor."

\section{Theme 4: Expectancy towards discharge}

When they have recovered from their psychological agony, as well as the physical danger of death from the disease, these patients regain their vitality and vigilance, and look forward to discharge from the hospital with good humor and a desire to return to their normal lives.

\section{Uncertainty towards recurrence}

When hospital discharge was approaching, these patients tended to expand their mental horizons, anticipating their future lives outside the hospital. Even if the physical symptoms of their illness had mostly disappeared, their memory of the panic about COVID-19 infection formed amid the pandemic may remain with them for a long time. This psychological scar applies to the patients' vigilance of self-protection in the society to which they are returning, and gives them a fair amount of uncertainty towards the possibility of recurrence of the disease, as one participant responded, $P 9$ : "I have seen many people tested positive in the [COVID-19] recurrence since the sixth day of the New Year. What if this happens again? I don't want to think about it; otherwise, I cannot sleep."Five of the participants even responded that they were worrying whether they were given enough medication for future use. For example, P13 "I want to have some anti-virus medicine for future use. I asked the doctor to give me some of this medicine."

\section{Longing for normality}

Passing the arc of life and death while in retrospect of the past and presence during the treatment, patients start to walk in the equipoise between the congenial imagination of the future and the unpredictable proceeding of life. All of the recovering patients in this study expressed plans for their future lives after hospital discharge; here's one example, $P 7$ : "I wish our city could be back to normal soon so that we may return to the classroom. I used to adore a pop star. Now I just want to study more and become useful to society."

\section{Theme 5: Support during hospitalization}

Just like medication to a physical treatment, support is the psychological therapy that saves patients from negative emotions and psychological agony. Support may originate from sources as diverse as family, healthcare professionals, and government.

\section{Family support}

In all these COVID-19 patient interviews, the participants concurred that what bolstered them during the long journey through the devastation of the illness and the uncertain progress of recovery was desire to be reunited with their families. A few examples of their sentiments follow, P7: "Every day I talked to my dad and sister through video calls about my treatment. We were all in different places. We encouraged each other and prayed for a reunion someday." P12: "I monitored the instant updates of my family members. Eight of us were assigned to five different places, but we encouraged each other every day (smiling)."

\section{Healthcare professional support}

Another and indispensable type of support that patients were desperate for was from the healthcare professionals (i.e., doctors, nurses, hospital staff). Observed from their daily care, even subtle actions of the healthcare professionals would produce a strong sense of gratitude from the patients. P6: "Watching the nurses working very hard, I felt steady and settled. The nurses delivered every one of my meals, and every bottle of water to me. If there was no assistance from the nurses, both my wife and I could have been dead." P2: "I told one nurse that I wanted to get a haircut, which, as you saw, everybody wanted. The next day, a group of nurses came to solve this problem for us."

\section{Governmental support}

Another crucial support that materialized and catalyzed the psychological support previously mentioned was from the local and central governments. All the patients expressed gratitude during the interviews to the government that backed the treatment, both financially and with physical efforts. P6: "I did not give up my treatment, because the government provided the money to pay for it . . I really want to thank the government for all the albumin infusions and healthy meals. And I thank you as well as our government."

\section{Discussion}

The complicated psychological experiences of patients with COVID-19 is disclosed throughout the interviews of this phenomenological study. Five themes were generated: misjudgment of the disease before diagnosis, negative emotions at the diagnosis, psychological agony during hospitalization, expectancy towards discharge, and support during hospitalization.

At the outbreak of COVID-19, people were underestimating the impact of the virus as a result of their lack of information and indifference towards the disease. The lack of information was demonstrated as some of the study participants declared they had never heard of the COVID-19 disease; 
some also mentioned the information they received from the media was ambiguous and hard to understand. Without an adequate understanding of COVID-19's transmission routes, participants neglected their self-protection at the early stage of the outbreak, and were unintentionally exposed to the virus during daily activities. These findings are consistent with what Wolf found during the early weeks of the COVID-19 outbreak in the United States [20]. Wolf, et al. [20] found that many patients with chronic conditions were not fully aware of the potential impact the infection could have on their health; and even knowing the virus was transmittable, they were still not taking proactive self-protective measures, which reflected the public's indifference at the outbreak of a new and unknown disease.

Knowing one's positive test result elicited an overwhelming amount of negative emotions in these patients. Multiple study participants were daunted by the fact that their family members could have tested positive before they did. The participants all panicked at first and then felt desperate, as they had never expected the disease to worsen so quickly, and believed the poor prognosis of the disease would disrupt every aspect of their lives. For instance, one participant experienced panic when he learned his whole family had been infected, even though he was himself about to be admitted to the hospital. The patients' negative emotions at diagnosis in our study are supported by other literature [21], which also reported patients were frightened of developing the severe symptoms of COVID-19 when they were diagnosed. The initial response of fear and an overwhelming amount of negative emotions at diagnosis were reported from patients in multiple countries [22-24]. In addition, the potential infection of entire families and the death of loved ones understandably brought these patients a sense of desperation. Patients with a deceased family member due to COVID-19 suffered bereavement and grief, which could devolve into a state of desperation [25]. Similar psychosocial impacts were found in the outbreak of Severe Acute Respiratory Syndrome (SARS), Middle East Respiratory Syndrome (MERS), and influenza virus H1N1 [26-28].

The psychological agony of the hospitalized patients in our study was shown in the deep concern they experienced over family separation that occurred when their families were broken apart by the pandemic (in some cases, several family members being sent to different hospitals for treatment), which naturally made these patients concerned, anxious, and stressed about other members of their families. This concern had shown up in public media, and yet had not been reported in any literature. Patients were also concerned about their own recovery in the hospital. Due to the fact that there were no antiviral drugs targeted to COVID-19, and the existing treatment was not as effective as expected, participants felt uncertain about the treatment they received. In addition, healthcare specialists were themselves uncertain about the treatment and the disease trajectory of COVID-19 [29-30]. Even though the participants were uncertain about the effectiveness of their COVID-19 treatment, our study interviews revealed they also had a desire for excessive treatment, which may have been a result of either their worries about the pace of recovery, or their strong belief in and reliance on life support treatment, such as the use of oxygen.

Desiring extra treatment could also be interpreted as the patients' compensating for their uncertainty about their course of treatment, in which they called for more personal medical attention from the healthcare providers. Their vigilance of self-protection during hospitalization was consistent with findings in the studies of the SARS and H1N1 epidemics. For example, vigilance and worry were omnipresent and fast-spreading in each patient's later period of recovery amid the SARS and H1N1 epidemics [31-33]. We found, similarly, that some participants who were close to discharge were strongly vigilant about their recovery, and objected to sharing their hospital rooms with newly diagnosed COVID-19 patients because of the belief they would be re-infected.

The participants' expectancy towards hospital discharge consisted of uncertainty towards recurrence and longing for a return to normal life. As of April 2020, there was no evidence that the antibodies generated after recovery could prevent the patient from a second infection [34]. Moreover, people were overwhelmed by news of numerous anecdotal re-infection cases of COVID-19 reported in the media. Another characteristic of expectancy of the study participants was their longing for normal lives after discharge. This hope for a return to normality brought the participants something deeper to the meaning of their lives, as some of them chose to reaffirm the value and purpose of life, some decided to alter unhealthy behaviors, and others began to prioritize their family responsibilities. Patients' longing for normality was a novel finding that has not been addressed in other literature.

All of the three subthemes under support during hospitalization can be traced to previous literature. Sun, et al. [35] stated that positive emotions associated with the support patients received came from multiple sources, such as their family, the medical team treating them, government, and social groups. In our study, all the participants were grateful when describing the support that they had received from their families, healthcare professionals, and the government. The participants in our study believed that family is inseparable from their psychological support. Lidell [36] suggested that emotional support within the family should always be the first priority. This is consistent with our results, that the hope of reuniting with family members becomes a huge motivation for participants to actively engage in treatment. The support from healthcare professionals resonates with the findings in other studies $[37,38]$. It is imperative that healthcare professionals recognize the irreplaceable support they can offer to patients with comorbidities by educating them with effective health information during this public health crisis [37]. Moreover, governmental support is also consistent with previous studies. At the end of January, the Chinese Central Health Authority released the "Principles for Emergency Psychological Crisis Intervention for COVID-19 Pneumonia Epidemic" to recognize the key roles professionally trained mental health therapists played in providing mental health support to patients during the crisis [39]. Overall, synthesizing multidimensional supports to alleviate patients' negative emotions and psychological agony is essential on their way to recovery. 
To our knowledge, this is the first study to explore the psychological experience among patients with COVID-19 using a phenomenological approach. Our findings suggest that early psychological assessment with personalized interventions to enhance mental health is imperative to prevent adverse emotions after discharge for patients with COVID-19. In addition, our results provide a vane for future studies on psychological and mental health among patients with COVID-19 in different stages during this pandemic.

\section{Conclusion}

This study provides a comprehensive understanding of the psychological experiences of patients with COVID-19. Patients with COVID-19 in this study sample had complicated psychological experiences from prior-to-diagnosis to discharge. These patients went through a process of misjudgment of the disease before diagnosis, a range of negative emotions at diagnosis, psychological agony during hospitalization, expectancy towards discharge, as well as a series of supports during hospitalization that catalyzed the process. Healthcare providers should be aware of a series of complicated psychological experiences of patients with COVID-19 that were shown in our study, and should develop mental health strategies and interventions accordingly.

\section{Acknowledgement}

The authors thank the COVID-19 medical team from the $988^{\text {th }}$ Hospital of People's Liberation Army and thank the nursing department at Taikang Tongji Hospital for their cooperation.

\section{Conflict of Interest}

The authors have no conflicts of interest to report.

\section{Author's Contribution}

Siqian Wang and Yingjie Liu contributed equally and are co-first authors.

\section{References}

1. World Health Organization (2020) Naming the coronavirus disease (COVID-19) and the virus that causes it.

2. World Health Organization (2020) Pneumonia of unknown cause - China.

3. Huang C, Wang Y, Li X, et al. (2020) Clinical features of patients infected with 2019 novel coronavirus in Wuhan, China. Lancet 395: 497-506.

4. Bassetti M, Vena A, Giacobbe DR (2020) The novel Chinese coronavirus (2019-nCoV) infections: Challenges for fighting the storm. European Journal of Clinical Investigation 50: e13209.

5. World Health Organization (2020) Coronavirus.

6. Backer JA, Klinkenberg D, Wallinga J (2020) Incubation period of 2019 novel coronavirus (2019-nCoV) infections among travelers from Wuhan, China, 20-28 January 2020. Eurosurveillance 25: 2000062.

7. Wu C-I, Postema PG, Arbelo E, et al. (2020) SARS-CoV-2, COVID-19, and inherited arrhythmia syndromes. Heart Rhythm 17: $1456-1462$.
8. Wang D, Hu B, Hu C, et al. (2020) Clinical characteristics of 138 hospitalized patients with 2019 novel Coronavirus-infected pneumonia in Wuhan, China. JAMA 323: 1061-1069.

9. World Health Organization (2020) Substantial investment needed to avert mental health crisis.

10. Cao W, Fang Z, Hou G, et al. (2020) The psychological impact of the COVID-19 epidemic on college students in China. Psychiatry Research 287: 112934.

11. Lai J, Ma S, Wang Y, et al. (2020) Factors associated with mental health outcomes among health care workers exposed to coronavirus disease 2019. JAMA Network Open 3: e203976.

12. Wang C, Pan R, Wan X, et al. (2020) Immediate psychological responses and associated factors during the initial stage of the 2019 coronavirus disease (COVID-19) epidemic among the general population in China. International Journal of Environmental Research and Public Health 17: 1729.

13. Xiao H, Zhang Y, Kong D, et al. (2020) The effects of social support on sleep quality of medical staff treating patients with coronavirus disease 2019 (COVID-19) in January and February 2020 in China. Med Sci Monit 26: e923549.

14. Minichiello V, Aroni R, Hays TN (2008) In-depth interviewing: Principles, techniques, analysis. ( $3^{\text {rd }}$ edn), Pearson Education Australia.

15. Colaizzi PF (1978) Psychological research as the phenomenologist views it. In: RS Valle, M King, Existential-phenomenological alternatives for psychology, Oxford University Press, 48-71.

16. Carter N, Bryant-Lukosius D, Di Censo A, et al. (2014) The use of triangulation in qualitative research. Oncology Nursing Forum 41: 545-547.

17. Pitney WA (2004) Strategies for establishing trustworthiness in qualitative research. International Journal of Athletic Therapy and Training 9: 26-28.

18. Carcary M (2009) The research audit trial-enhancing trustworthiness in qualitative inquiry. ECRM 7: 11-24.

19. Tufford L, Newman P (2012) Bracketing in qualitative research. Qualitative Social Work 11: 80-96.

20. Wolf MS, Serper M, Opsasnick L, et al. (2020) Awareness, attitudes, and actions related to COVID-19 among adults with chronic conditions at the onset of the U.S. outbreak. Annals of Internal Medicine 173: 100-109.

21. Xiang Y-T, Yang Y, Li W, et al. (2020) Timely mental health care for the 2019 novel coronavirus outbreak is urgently needed. The Lancet Psychiatry 7: 228-229.

22. Casanova M, Bagliacca EP, Silva M, et al. (2020) How young patients with cancer perceive the COVID-19 (coronavirus) epidemic in Milan, Italy: Is there room for other fears? Pediatric Blood \& Cancer 67: e28318.

23. Kim SW, Su KP (2020) Using psychoneuroimmunity against COVID-19. Brain, Behavior, and Immunity 87: 4-5.

24. Yao TT, Qian JD, Zhu WY, et al. (2020) A systematic review of lopinavir therapy for SARS coronavirus and MERS coronavirus-A possible reference for coronavirus disease-19 treatment option. Journal of Medical Virology 92: 556-563.

25. Li W, Yang Y, Liu ZH, et al. (2020) Progression of mental health services during the COVID-19 outbreak in China. International Journal of Biological Sciences 16: 1732-1738. 
26. Kim HC, Yoo SY, Lee BH, et al. (2018) Psychiatric findings in suspected and confirmed Middle East respiratory syndrome patients quarantined in hospital: A retrospective chart analysis. Psychiatry Investigation 15: 355-360.

27. Lau JT, Griffiths S, Choi KC, et al. (2010) Avoidance behaviors and negative psychological responses in the general population in the initial stage of the H1N1 pandemic in Hong Kong. BMC Infectious Diseases 10: 139.

28. Yip PSF, Cheung YT, Chau PH, et al. (2010) The impact of epidemic outbreak. Crisis 31: 86-92.

29. Ueda M, Martins R, Hendrie PC, et al. (2020) Managing cancer care during the COVID-19 pandemic: Agility and collaboration toward a common goal. Journal of the National Comprehensive Cancer Network 18: 366-369.

30. Wu JT, Leung K, Leung GM (2020) Now casting and forecasting the potential domestic and international spread of the 2019$\mathrm{nCoV}$ outbreak originating in Wuhan, China: A modelling study. Lancet 395: 689-697.

31. Lau JTF, Yang X, Pang E, et al. (2005) SARS-related perceptions in Hong Kong. Emerg Infect Dis 11: 417-424.

32. Lau JTF, Yang X, Tsui HY, et al. (2006) Positive mental health-related impacts of the SARS epidemic on the general public in
Hong Kong and their associations with other negative impacts. Journal of Infection 53: 114-124.

33. Lau JTF, Griffiths S, Choi KC, et al. (2009) Widespread public misconception in the early phase of the H1N1 influenza epidemic. Journal of Infection 59: 122-127.

34. World Health Organization. (2020) "Immunity passports" in the context of COVID-19.

35. Sun N, Wei L, Shi S, et al. (2020) A qualitative study on the psychological experience of caregivers of COVID-19 patients. American Journal of Infection Control 48: 592-598.

36. Lidell E (2002) Family support-a burden to patient and caregiver. European Journal of Cardiovascular Nursing 1: 149-152.

37. Latham S, Lamson J, Williams S, et al. (2020) Maintaining emotional well-being during the COVID-19 pandemic: A resource for your patients. Chronic Obstr Pulm Dis 7: 76-78.

38. Song Z, Hu Y, Zheng S, et al. (2020) Hospital pharmacists' pharmaceutical care for hospitalized patients with COVID-19: Recommendations and guidance from clinical experience. Research in Social and Administrative Pharmacy.

39. National Health Commission of China (2020) Principles of the emergency psychological crisis interventions for the new coronavirus pneumonia (in Chinese).

DOI: $10.36959 / 545 / 383$

Copyright: (c) 2020 Wang S, et al. This is an open-access article distributed under the terms of the Creative Commons Attribution License, which permits unrestricted use, distribution, and reproduction in any medium, provided the original author and source are credited. 